OPEN ACCESS

Edited by:

Kristy Wallmo,

Department of Commerce, USA

Reviewed by:

Christian T. K.-H. Stadtlander,

Independent Researcher, USA

Leif Anderson,

NOAA Fisheries, USA

${ }^{*}$ Correspondence: Keldi Forbes,

Fisheries and Oceans Canada, 200 Kent Street, Ottawa,

ON K1A OE6, Canada Keldi.Forbes@dfo-mpo.gc.ca

Specialty section:

This article was submitted to Marine Affairs and Policy, a section of the journal Frontiers in Marine Science

Received: 13 June 2015 Accepted: 31 August 2015 Published: 23 September 2015

Citation:

Forbes K, Boxall PC, Adamowicz WL and De Maio Sukic A (2015) Recovering Pacific rockfish at risk: the economic valuation of management actions. Front. Mar. Sci. 2:71.

doi: 10.3389/fmars.2015.00071

\section{Recovering Pacific rockfish at risk: the economic valuation of management actions}

\author{
Keldi Forbes ${ }^{1 *}$, Peter C. Boxall ${ }^{2}$, Wiktor L. Adamowicz ${ }^{2}$ and Alejandro De Maio Sukic ${ }^{1}$ \\ ${ }^{1}$ Fisheries and Oceans Canada, Ottawa, ON, Canada, ${ }^{2}$ Department of Resource Economics and Environmental Sociology, \\ University of Alberta, Edmonton, $A B$, Canada
}

Over 35 species of rockfish are found along Canada's Pacific coast, some of which have been considered for listing under Canada's Species at Risk Act. We estimate Canadians' welfare for recovery of a representative Pacific rockfish species using referendum-style stated preference methods administered to a sample of the Canadian public via an internet panel. Hypothetical recovery programs were presented as options to a baseline of current management measures. The programs resulted in varying long term outcomes distinguished by species' future population projections. An increase in household taxes for a fixed 10 year period was employed as the proposed payment mechanism. The econometric analysis found positive and significant welfare measures for all management programs, as well as sensitivity to scope. Willingness to pay ranged from $\$ 48$ to $\$ 180$ per year per household depending on the recovery program valued. Welfare measures were found to differ significantly between those who believed their responses to be consequential and those who did not. The former provided measures that were significantly higher than the latter. We conclude with a discussion of the findings in relation to recent literature on consequentiality and incentive compatibility of stated preference questions.

Keywords: rockfish, welfare measures, consequentiality, species at risk recovery

\section{Introduction}

The introduction of Canada's Species at Risk Act in 2002, and the regulatory requirements put forward by the Canadian Federal Government's Cabinet Directive on Regulatory Management, highlight the importance of accurate and complete benefit cost analyses (BCA) of species listing decisions. While cost information and data are often readily available, corresponding benefit information is not.

Over 35 species of rockfish are found along Canada's Pacific coast, of which nine have been considered for listing under the Species at Risk $A c t^{1}$. While numerous stated preference studies estimating non market values associated with environmental and species protection have been performed, to the best of our knowledge there are no studies addressing Canadian rockfish populations or similar species and associated recovery plans. The closest work we are aware of is that of Anderson et al, which examined the impacts of management programs involving partial and full recreational fishing area closures to benefit rockfish in Puget Sound on recreational fishers (Anderson et al., 2013). This study estimates Canadian passive use benefits

\footnotetext{
${ }^{1}$ Government of Canada, Species at Risk Public Registry. (Available online at: https://www.registrelep-sararegistry.gc.ca/).
} 
associated with the protection and recovery of a representative rockfish species using a stated preference approach.

This paper also discusses the impact of perceived consequentiality on estimated welfare measures. The questionnaire presented hypothetical but realistic and possible management programs for recovering the rockfish species. Respondents who indicated they believed the results would influence marine policy programs were identified; their welfare measures were assessed both jointly and separately with the full sample. An issue of on-going interest in stated preference valuation is the assessment of the incentive compatibility of the survey instrument. Carson and Groves argued that if a respondent views survey results as potentially influencing an agency's actions, and the respondent is invested in the outcomes of those actions, standard economic theory applies. In this analysis we examine the impact of perceived consequentiality on welfare measures. Emerging literature suggests that this approach provides estimates of welfare measures that are incentive compatible (Vossler et al., 2012). Vossler et al. found a modest positive bias on WTP estimates was removed when respondents believed that the survey results would have more than a weak impact on policy. This is in seeming contrast to what Vossler and Watson found when comparing survey responses and real world referendum results on support of a conservation program to be funded by a property tax increase. Their results showed that an under-prediction of support for the program, and a negative bias on WTP, disappeared when respondents who did not believe their survey vote would be consequential were removed from the estimation (Vossler and Watson, 2013).

Thus, the contributions of the paper are empirical (presenting welfare measures associated with the recovery of a little-studied Canadian species), and methodological, (identifying a key sample segment to focus on as well as survey design insights). We also employ a novel empirical approach by jointly estimating the willingness to pay for conservation programs and the probability of a respondent believing that the result will influence policy.

\section{Materials and Methods}

\section{Stated Preferences and Non Market Value Estimation}

Without observable behavior related to the general Canadian populations' quantitative values regarding rockfish conservation, a stated preference approach was the sole estimation option. Economic values associated with rockfish conservation stem from a shift in an individual's utility due to the knowledge that a management program that benefits the continued existence of the species is in place. An individual's utility may change with the implementation of a management program that benefits the species due to a desire to use it in the future or bequeath it to future generations (Grafton et al., 2004).

Stated preference approaches ascertain values through questioning a respondent. Two established stated preference methods are contingent valuation $(\mathrm{CV})$ and choice experiments (CE). CV is widely recognized as an established technique for valuing wildlife enhancements (Randall, 1997). Respondents choose between differing states of the world. This may include payment for an improved state of the world such as an increase in wildlife populations, indicating willingness to pay (WTP).

A variant of the traditional CV method was selected as the best option for this study due to a limited number of alternatives in practice, and the fixed nature of the attributes apart from cost within each of the alternatives. Only three management programs were valued. Attributes such as the survival outcome for the species and the increased catch restrictions stayed constant within each management program presented. In addition, the economic value of introducing programs, rather than the attributes of the species or programs, is the relevant policy benefit component. A referendum approach was selected, as strategic behavior has been shown to be less likely with the referendum approach (Jakobson and Dragun, 2001).

In a referendum-style valuation study, respondents indicate a preference by voting for one of two options presented. It allows for believable presentation, and data that can by analyzed through well-developed techniques. Since, obtaining empirical values suitable for socio-economic analysis was the primary objective of the research, employing an established measurement technique to a previously unmeasured good was thought to be the best approach.

\section{Survey Instrument Design}

Central to the study was administration of a questionnaire containing qualitative, quantitative and program attribute-based stated preference questions. The questionnaire was developed over the years 2009-2010 with the aid of focus groups and pilot studies.

\section{Background, Baseline and Scenario Projections}

Development of the survey instrument involved collaboration with species experts to provide an accurate picture of the attributes of a representative Pacific rockfish population, and the characteristics including impacts of management programs. Information provision in stated preference surveys is a challenge, as respondents must be given sufficient information to make a meaningful decision while staying within a manageable survey length and without biasing their choices. The survey instrument specified that there were over 35 species of rockfish widely dispersed geographically along the Pacific coast, and stated that the management programs being valued were to benefit a single representative rockfish species. Descriptions of other species listed under the Species at Risk Act were included, in an effort to ensure respondents considered that other species may also require management programs when indicating whether they would vote for management programs benefitting the rockfish species.

Central to the welfare estimates were the baseline and scenario projections. The respondents were asked to choose between what was described as the "current management scenario" in which the species continued on its present population trajectory, with no new management measures introduced and no additional costs to the respondent, and a "proposed management scenario" with a reduced total allowable catch (TAC) levels, and costs. 
Each management scenario had an associated distinct species population trajectory.

Respondents were asked how they would vote on two options. The first, the current management option (baseline), had no new management measures introduced, no additional costs, and the species would be endangered in 40 years. The alternative option was one of three new management programs. Each new program had an additional cost, which was selected at random from $\$ 1, \$ 10, \$ 50, \$ 150, \$ 300, \$ 600$, annually for 10 years. See Table 1 for a management program summary. Bids were selected to have a relatively large proportion choosing the program at the lowest price, and a relatively small proportion choosing the program at the highest price. However, we also recognize that bid levels must be credible to respondents and probed on this issue in the focus groups and in debriefing questions. Nonetheless, bid design is a concern in all stated preference studies.

The three programs possessed varying activity restrictions with corresponding socio-economic impacts, of which respondents were informed. The restrictions and impacts corresponded with species improvement 40 years into the future. This included a description of likely job losses under certain management programs. While the description was included for transparency, respondents were told that compensation would occur to ensure that respondents' passive use values for Pacific Rockfish were being measured as opposed to their values related to jobs. Species improvement was described using the classifications under Canada's Species at Risk Act (Extinct/Extirpated, Endangered, Threatened, Special Concern, Not at Risk). Respondents saw a definition of each classification as well as an example of a species corresponding to each. This served a dual purpose. It ensured respondents understood the definitions while reminding them that other species also face difficulties. Each respondent compared the three programs to the status quo and voted (as in Figure 1). The order in which each respondent saw the programs was randomized in the administration of the instrument.

\section{Focus Groups}

Four focus groups were conducted using the questionnaire to ascertain the suitability of the instrument and the comprehension of the provided information by potential respondents. The groups were held across Canada to reduce the possibility of regionally specific issues, and included between 9 and 12 randomly recruited participants using random digit dialing telephone recruitment. A challenge with the topic of the study is potentially the low knowledge level respondents may have on the survey topic. Focus group discussions and responses to a number of the questions indicated that many Canadians were unfamiliar with the Species at Risk Act, as well as rockfish species themselves. To present the complex issues while staying within a manageable questionnaire length required a delicate balance. The focus groups provided direct feedback on areas they felt required more detailed information to allow them to make a decision, and which areas could be abbreviated. Starting points for WTP value estimates, necessary for contingent valuation questions, were also sought. Following each focus group the survey instrument was updated and refined.

Socio-demographic questions addressing age, gender, marital status, and location were also collected. Respondents were asked if they or their family members were involved in the fishing industry and whether they belonged to an environmental organization. This individual specific information was needed for understanding heterogeneity in the responses to the referendum questions. From a policy perspective assessing distributional impacts of the proposed management plans may be necessary. The results from these questions were assessed through statistical summaries of the various variables as well as their inclusion in econometric models of voting behavior.

\section{Pilot Tests}

Once the focus groups and adjustments were completed, the questionnaire went through two pilot tests using a combined total of 469 respondents. These pilot tests allowed for further calibration of the WTP values included in the contingent valuation questions. Ultimately, the survey was finalized with some minor changes, including an increased bid range and a simplified experimental design.

\section{Addressing Hypothetical Bias}

Steps were taken to minimize potential hypothetical bias in stated preference responses. Four different strategies were employed: (1) a cheap talk script was included in the survey before the choice

TABLE 1 | Management programs presented to respondents.

\begin{tabular}{|c|c|c|}
\hline Program 1 & Program 2 & Program 3 \\
\hline $\begin{array}{l}\text { This Rockfish is still allowed to be caught } \\
\text { through incidental catch }\end{array}$ & $\begin{array}{l}\text { This Rockfish is still allowed to be caught through } \\
\text { incidental catch }\end{array}$ & $\begin{array}{l}\text { This Rockfish is still allowed to be caught } \\
\text { through incidental catch }\end{array}$ \\
\hline Catch level stays the same & Catch level would be reduced by $33 \%$ & Catch level would be reduced by $66 \%$ \\
\hline $\begin{array}{l}\text { Catch levels of other species in the trawl and } \\
\text { hook and line fleets will be reduced by } 5 \%\end{array}$ & $\begin{array}{l}\text { Catch levels of other species in the trawl and hook } \\
\text { and line fleets will be reduced by } 20 \%\end{array}$ & $\begin{array}{l}\text { Catch levels of other species in the trawl and } \\
\text { hook and line fleets will be reduced by } 45 \%\end{array}$ \\
\hline $\begin{array}{l}\text { A small amount jobs and income will be } \\
\text { affected. Those affected will be compensated } \\
\text { through a separate process that includes a } \\
\text { variety of programs }\end{array}$ & $\begin{array}{l}\text { A moderate amount jobs and income will be } \\
\text { affected. Those affected will be compensated } \\
\text { through a separate process that includes a variety } \\
\text { of programs }\end{array}$ & $\begin{array}{l}\text { A large amount jobs and income will be } \\
\text { affected. Those affected will be compensated } \\
\text { through a separate process that includes a } \\
\text { variety of programs }\end{array}$ \\
\hline
\end{tabular}

Species would be threatened in 40 years

The species would be special concern in 40 years

The species would be not at risk in 40 years 
Please indicate which option you would vote for if there was a national vote (referendum) on managing this species:

\begin{tabular}{|c|c|c|}
\hline & $\begin{array}{l}\text { Current Management } \\
\text { Option }\end{array}$ & $\begin{array}{c}\text { Proposed } \\
\text { Management Option }\end{array}$ \\
\hline Strategy for protection & No new regulations & Program 3 \\
\hline \multirow[t]{2}{*}{$\begin{array}{l}\text { Listing status } \\
\text { ( in } 40 \text { years) }\end{array}$} & $\begin{array}{c}\text { In } 40 \text { years the listing } \\
\text { status for this species } \\
\text { will be: }\end{array}$ & $\begin{array}{c}\text { In } 40 \text { years the listing } \\
\text { status for this species } \\
\text { will be: }\end{array}$ \\
\hline & Endangered & Not at Risk \\
\hline $\begin{array}{l}\text { Probability of extinction } \\
\text { (in } 40 \text { years) }\end{array}$ & Very High & None \\
\hline $\begin{array}{l}\text { Increased cost to your } \\
\text { household in extra } \\
\text { taxes every year for } 10 \\
\text { years }\end{array}$ & $\$ 0$ & $\$$ \\
\hline
\end{tabular}

Please remember this is a cost estimate for the program. The range of costs may vary depending on economic conditions and other factors.

The increased taxes would be used to monitor and enforce fishermen's and fishery compliance with the recovery programs

FIGURE 1 | Survey question example comparing Program 3 to the status quo.

questions that asked respondents to make choices as if these were real transactions; (2) multiple voting scenarios in randomized order were given to each respondent; (3) follow up questions on respondents' level of certainty regarding their votes were included and uncertain responses were identified; and finally (4) additional follow up questions designed to identify strategic voters were included following elicitation of vote choices.

Cleaning the data involved identification of speeders, protest votes and yea-sayers. Speeders are respondents who race through a survey without considering the questions, their main objective being to complete the survey as swiftly as possible. As panel members receive reward points from the research company for each survey they participate in, there is some incentive for such behavior. Given the survey length, and the time focus group members took to complete the survey, respondents who finished the survey in less than $5 \mathrm{~min}$ were deemed speeders and removed from the data set. 
Protest voters are respondents who vote "no" as a way to make a point. In effect they give a \$0 WTP value, despite possessing a positive WTP. In the case of an issue such as rockfish conservation, they may be protesting government interference or tax increases. The referendum-style stated preference survey is thought to be potentially incentive compatible as respondents are limited in their opportunities to over- or under-estimate their WTP. The realistic and familiar voting format was designed to reinforce the need for realistic votes to the respondents, while the wording of the survey encouraged truthful responses and attempted to avoid inflammatory terms. However, the possibility of protest bids is a concern in stated preference studies. As such, follow up questions designed to identify such responses were included.

The follow up questions came immediately after the CV questions. Respondents were asked to "indicate the most important reason for voting the way [they] did." Multiple reasons were presented; respondents could also select "other." Respondents who voted yes for all three programs and indicated their reason to be they felt "species at risk should be protected at any cost" were classified as yea-sayers and removed from the data set prior to modeling (Blumenschein et al., 2008). Respondents who voted for the management program but indicated uncertainty regarding their choice were classified as no votes, as this has been shown to reduce hypothetical bias (Carson and Groves, 2007).

Respondents were also asked "to what degree [they] thought [their] votes would influence management programs chosen for the species," to help identify in part if the criteria of consequential survey questions was met. Those indicating a strong or very strong degree of impact were classified as believing the survey to be consequential. Vossler et al. (2012) identified the importance of perceived consequentiality on the part of the respondents, and the possible merit of including survey questions allowing researchers to control for it (Vossler et al., 2012). Following development of a game theoretic framework to analyze the incentive properties of discrete choice experiments they conducted a field experiment which showed a modest positive bias of WTP estimates was no longer present when respondents had a more than weak belief in the consequentiality of their responses. Note that it is still possible that respondents who considered the survey influential may feel that it may influence the policy (policy consequentiality) but not their tax payments (tax consequentiality).

\section{Survey Administration}

The questionnaire was administered online as this allowed a significant volume of information to be compressed into a more digestible format for respondents. Many color rich diagrams were included, as well as pop up definitions where necessary. The survey was completed by 1242 individuals out of 2215 sent invitations, for a response rate of $56 \%$. The survey sample was drawn from an internet panel of over 100,000 individuals maintained by Ipsos-Reid, and designed to be representative of the Canadian population based on a range of demographic characteristics. The panel required respondents to previously opt-in, and as such there may be inherent challenges associated with the representativeness of such panels (Government of Canada, 2006).

\section{Data Modeling and Value Estimation}

Stated preference data modeling techniques assume individuals make utility maximizing choices, and that their choices reflect their personal constraints such as time or income. For the CV data from this study, an individual $j$ 's utility for program $i$ can be written as:

$$
u_{i}=\propto+\beta P_{i}+\gamma H_{j}+\delta\left(y_{j}-C_{i}\right)+\varepsilon,
$$

where $u$ represents the respondent's indirect utility for program $i$, $P$ is a vector of program attributes, $H$ is a vector of individual and household characteristics of respondent $j, y$ represents respondent $j$ 's household income, and $C$ is program cost. The error term $\varepsilon$ represents factors that affect an individual's utility but are unknown to the researcher. The utility of the status quo of no management program is represented by $\propto$, the coefficient $\gamma$ represents the effect of household characteristics on utility of program selection, and $\beta$ represents the coefficients for the marginal utility of each program vs. the status quo. Finally, the marginal utility of money is represented by $\delta$.

When the individual chooses between a new management program and the status quo, it is akin to a vote for or against the new program. The respondents indicated whether, if faced with a referendum, they would choose the new management program complete with increased cost in the form of higher per household income tax (a "yes" choice), or the current management program with no increased cost (a "no" choice).

To estimate WTP for each management program, $u_{i j}$ represents respondent $j$ 's utility from management program $i$ and $u_{0 j}$ represents respondent $j$ 's utility from the status quo of no new management program. Assuming the first model from Table 3 with utility dependent solely on income and a management program $M_{i}$, WTP is equivalent to the amount of household income that would need to be taken away from respondent $j$ if management program $i$ is implemented to keep respondent $j$ 's utility at the same level. Then $u_{i}\left(\gamma-W T P_{j}, M_{i}\right)=$ $u_{0}\left(\gamma, M_{0}\right)$. Substituting the indirect utility function yields: $\alpha_{i}+$ $\delta\left(y_{j}-W T P_{j}\right)+\varepsilon_{i j}=\alpha_{0}+\delta y_{j}+\varepsilon_{0 j}$

which gives:

$$
W T P_{j}=\frac{\alpha_{i}-\alpha_{0}}{\delta}+\left(\varepsilon_{i j}-\varepsilon_{0 j}\right)
$$

Normalizing the utility of the status quo to 0 , and assuming the difference in error means is equal to 0 , gives $\mathrm{E}(\mathrm{WTP})=\alpha_{i} / \delta$.

To examine the possibility of a correlation between respondents' choices and their perceptions of survey consequentiality, a bivariate probit model was employed. This approach allowed for two equations to be estimated with correlated error disturbances. The first equation was an individual's choice between a new management program and the status quo dependent on program attributes, $y_{1}=\beta P_{i}+\cdots+\varepsilon_{1}$; and the second involved whether the respondent perceived the survey as consequential dependent on individual and household characteristics of respondent $j, y_{2}=\gamma H_{j}+\cdots+\varepsilon_{2}$. 


\section{Results and Discussion}

\section{Population Representation}

Key demographic characteristics were examined including age, gender, marital status, and income, to assess how the survey sample corresponded to the Canadian population as reflected in the 2006 Canada Census results (see Table 2). This is an important gauge of how representative the survey results were of the population of Canada.

The gender distribution for the survey sample was 50.89\% male and $49.11 \%$ female, compared to distribution found through the census of $48.95 \%$ male and $51.05 \%$ female. No respondents selected other or prefer not to answer. The age distribution of the survey sample differed somewhat from the most recent census distribution, with a slight over-representation of the 45-69 category, and a slight under-representation of the youngest and oldest populations. There are a number of probable reasons for this. The census groups 15-19 year olds together, while the survey was not administered to anyone

TABLE 2 | Comparison of survey demographics with the 2006 Canadian Census.

\begin{tabular}{|c|c|c|}
\hline Characteristic & Survey & Census \\
\hline Male (\%) & 50.89 & 48.95 \\
\hline \multicolumn{3}{|l|}{ AGE BY RANGE } \\
\hline $18-19^{\star}$ & $1.82 \%$ & $8.22 \%$ \\
\hline $20-24$ & $6.90 \%$ & $7.99 \%$ \\
\hline $25-29$ & $6.45 \%$ & $7.63 \%$ \\
\hline 30-34 & $7.84 \%$ & $7.76 \%$ \\
\hline 35-39 & $5.27 \%$ & $8.48 \%$ \\
\hline $40-44$ & $7.81 \%$ & $10.03 \%$ \\
\hline $45-49$ & $12.17 \%$ & $10.07 \%$ \\
\hline $50-54$ & $16.62 \%$ & $9.06 \%$ \\
\hline $55-59$ & $13.47 \%$ & $8.01 \%$ \\
\hline $60-64$ & $10.84 \%$ & $6.11 \%$ \\
\hline $65-69$ & $6.45 \%$ & $4.74 \%$ \\
\hline $70-74$ & $2.45 \%$ & $4.05 \%$ \\
\hline $75-79$ & $1.18 \%$ & $3.38 \%$ \\
\hline 80-84 & $0.64 \%$ & $2.48 \%$ \\
\hline$>85$ & $0.09 \%$ & $2.00 \%$ \\
\hline \multicolumn{3}{|l|}{ MARITAL STATUS } \\
\hline Single & $27.60 \%$ & $30.00 \%$ \\
\hline Couple & $58.40 \%$ & $56.00 \%$ \\
\hline Other & $14.00 \%$ & $14.00 \%$ \\
\hline \multicolumn{3}{|l|}{ INCOME BY RANGE } \\
\hline$<\$ 20000$ & $9.90 \%$ & $6.45 \%$ \\
\hline$\$ 20,000-\$ 39,999$ & $18.36 \%$ & $17.56 \%$ \\
\hline$\$ 40,000-\$ 59,999$ & $18.92 \%$ & $19.23 \%$ \\
\hline$\$ 60,000-\$ 79,999$ & $15.62 \%$ & $17.25 \%$ \\
\hline$\$ 80,000-\$ 99,999$ & $12.24 \%$ & $13.41 \%$ \\
\hline$\$ 100,000-\$ 124,999$ & $11.67 \%$ & $11.00 \%$ \\
\hline$\$ 125,000-\$ 149,999$ & $5.88 \%$ & $6.14 \%$ \\
\hline$>=\$ 150,000$ & $7.41 \%$ & $8.96 \%$ \\
\hline
\end{tabular}

*Survey age range 18-19 years, census age range 15-19 years. under 18. As such the census would be expected to have a significantly higher percentage of people in that category than is found here. The under representation of the highest age groups (those 70 years and older), may be due to lower levels of computer use in that age group (Statistics Canada Report, 2007). Marital status of the survey respondents (30.0\% single, $56.0 \%$ married, $14.0 \%$ domestic partnership) was closely reflected the Canadian population (27.6\% single, $58.4 \%$ married, $14.0 \%$ domestic partnership). Household income was divided into seven categories. The category with the largest discrepancy between survey respondents and the Canadian population was that of household income $<\$ 20,000$, with $9.90 \%$ compared to $6.45 \%$ respectively.

\section{Background Questions}

The survey contained background questions on the Species at Risk Act and fishing industry involvement. These questions were included to allow researchers to evaluate impacts on WTP, and potentially identify heterogeneous effects of management programs on individuals or groups.

\section{Familiarity with the Species at Risk Act}

This survey asked respondents their level of familiarity with the Species at Risk Act, to allow researchers to gauge the knowledge levels in the sample population. Respondents chose from one of three responses: very familiar, somewhat familiar, and not familiar. $1.449 \%$ and $27.29 \%$ of them said it was very familiar and somewhat familiar respectively, while $71.26 \%$ answered that they were not familiar with it at all. The low proportion of respondents identifying themselves as very familiar indicates that for most of the respondents, the majority of their Species at Risk Act knowledge will have come from the background information included in the survey.

\section{Fishing Industry Involvement}

The survey asked whether respondents or any members of the respondents' households presently or had previously worked in fishing-related industries, including processing plants, recreational fishing charters/tours, or commercial fishing or harvesting. Respondents could also answer none of the above or prefer not to answer. The majority of respondents (96.7\%) chose none of the above; $0.5 \%$ indicated they or family members currently work or had previously worked in commercial fishing or harvesting; $1 \%$ indicated the same for recreational charters/tours; and $1 \%$ for aquatic species processing plants. The remainder of respondents preferred not to answer. This level of industry and direct involvement with the species amongst respondents suggests that the values found will be largely passive use in nature.

\section{Modeling \\ Binary Probit Model}

Probit models were used in the analysis of the choice questions to develop estimates of WTP values for programs by specific outcome. Each of the respondents saw three choice questions representing three possible program outcomes. These were contrasted with a status quo outcome representing the current management actions and forecast outcome. The respondents 
indicated whether, if faced with a referendum, they would choose the new management program complete with increased cost (a "yes" choice), or the current management program with no increased cost (a "no" choice). The order of questions was randomized between respondents. As well, each of the three programs had six possible costs, one of which was randomly assigned to each question.

We developed five probit models to estimate Canadians' willingness to pay for management programs benefitting a Pacific Rockfish based on the utility function described before. The tax increases associated with the management programs was coded as a continuous variable. Household income and age were converted from an ordinal scale to a continuous variable using the midpoints of categories. Whether or not the respondent works in the fishing industry, is a member of an environmental organization, has children, and their gender, were modeled as indicator variables. The models assessed the likelihood of respondents voting for a management program with one of three improved outcomes for the species over 40 years vs. the status quo of no new management measures. Outcomes of "Threatened" and "Special Concern" were included as indicator variables, with the outcome of "Not at Risk" reflected in the constant.
Econometric results of the five models are found in Table 3. The first four models contained cost and program outcomes as independent variables. Model 1 was estimated with the first vote of each respondent. Model 2 was estimated with the first vote results of respondents who believed the study would have an impact on policy. The first and second models used a binary probit model. Model 3 was estimated with results from all votes from respondents who indicated they believed the study would have an impact on policy. Model 4 was estimated with results from all three votes. Model 5 was estimated with all vote results, and includes additional socio-demographic characteristics.

Given that the standard binary probit model treats each vote as an independent observation, biased standard errors of the coefficients may result when each respondent provides several votes (Guilkey and Murphy, 1993). To alleviate this, the three models which included multiple votes used a random effects structure for the error components. Using this approach, two independent components make up the error term. One represents an unobservable characteristic for each individual, while the other varies both for individuals and votes.

Parameters from all five models were used to estimate positive and significant WTP values for management programs benefiting a Pacific rockfish species (see Table 4). WTP was estimated as an

TABLE 3 | Estimates of probit regression parameters.

\begin{tabular}{|c|c|c|c|c|c|}
\hline & \multicolumn{2}{|c|}{ Probit first choice } & \multicolumn{3}{|c|}{ Random effects probit all choices } \\
\hline & Model 1 & Model 2 Yes to influence & Model 3 Yes to influence & Model 4 & Model 5 \\
\hline \multirow[t]{2}{*}{ Constant } & $0.6037^{\star \star \star}$ & $0.9357^{\star \star *}$ & $1.2565^{\star \star \star}$ & $0.9471^{\star \star *}$ & $0.3871^{\star \star}$ \\
\hline & $(0.0815)$ & $(0.2510)$ & $(0.2091)$ & $(0.0697)$ & $(0.1828)$ \\
\hline \multirow[t]{2}{*}{ Cost } & $-0.0033^{\star \star \star}$ & $-0.0041^{\star \star *}$ & $-0.0055^{\star \star \star}$ & $-0.0058^{\star \star \star}$ & $-0.0057^{\star \star \star}$ \\
\hline & $(0.0002)$ & $(0.0007)$ & $(0.0006)$ & $(0.0002)$ & $(0.0002)$ \\
\hline \multirow[t]{2}{*}{ Threatened } & $-0.1978^{\star \star}$ & -0.3058 & $-0.5967^{\star \star}$ & $-0.4487^{\star \star \star}$ & $-0.4482^{\star * \star}$ \\
\hline & (0.0993) & $(0.2960)$ & $(0.2441)$ & $(0.0726)$ & $(0.0727)$ \\
\hline \multirow[t]{2}{*}{ Special concern } & -0.0748 & -0.0387 & -0.0453 & $-0.1941^{\star \star \star}$ & $-0.1958^{\star \star \star}$ \\
\hline & $(0.1002)$ & $(0.2941)$ & $(0.2182)$ & $(0.0725)$ & $(0.0727)$ \\
\hline \multirow[t]{2}{*}{ Children } & - & - & - & - & 0.0610 \\
\hline & & & & & $(0.1012)$ \\
\hline \multirow[t]{2}{*}{ Male } & - & - & - & - & 0.0226 \\
\hline & & & & & (0.0920) \\
\hline \multirow[t]{2}{*}{ Household Income } & - & - & - & - & $0.0047^{\star \star \star}$ \\
\hline & & & & & $(0.0010)$ \\
\hline \multirow[t]{2}{*}{ Age } & - & - & - & - & 0.0028 \\
\hline & & & & & $(0.0033)$ \\
\hline \multirow[t]{2}{*}{ Fish industry } & - & - & - & - & 0.3716 \\
\hline & & & & & $(0.2649)$ \\
\hline \multirow[t]{2}{*}{ Enviro Org } & - & - & - & - & $0.5556^{\star \star \star}$ \\
\hline & & & & & $(0.1917)$ \\
\hline \multirow[t]{2}{*}{ Rho } & - & - & $0.6225^{\star \star *}$ & $0.5560^{\star * *}$ & $0.5418^{* * *}$ \\
\hline & & & $(0.0737)$ & $(0.0264)$ & $(0.0271)$ \\
\hline Log Likelihood & -624.55 & -70.396 & -205.88 & -1678.09 & -1783.58 \\
\hline Number of votes & 1097 & 134 & 402 & 3291 & 3291 \\
\hline Number of individuals & 1097 & 134 & 134 & 1097 & 1097 \\
\hline
\end{tabular}

${ }^{\star * \star}$ Significant at $1 \%$ level.

${ }^{\star}$ Significant at $5 \%$ level. 
TABLE 4 | Summary of WTP estimates per household per year for 10 years found through random effect probit models with standard errors.

\begin{tabular}{|c|c|c|c|c|c|}
\hline & \multicolumn{2}{|c|}{ Probit first choice } & \multicolumn{3}{|c|}{ Random effects probit all choices } \\
\hline & Model 1 & Model 2 Yes to influence & Model 3 Yes to influence & Model 4 & Model 5 \\
\hline \multirow[t]{2}{*}{ Species outcome: Not at Risk } & $\$ 180.32$ & $\$ 228.23$ & $\$ 229.41$ & $\$ 164.01$ & $\$ 126.35$ \\
\hline & $(21.59)$ & $(54.79)$ & $(33.91)$ & $(10.46)$ & $(31.33)$ \\
\hline \multirow[t]{2}{*}{ Species outcome: Special Concern } & - & - & - & $\$ 130.49$ & $\$ 92.26$ \\
\hline & & & & $(11.39)$ & $(30.74)$ \\
\hline \multirow[t]{2}{*}{ Species outcome: Threatened } & $\$ 121.23$ & - & $\$ 120.47$ & $\$ 86.47$ & $\$ 48.32$ \\
\hline & $(20.77)$ & & (39.04) & $(10.85)$ & (31.59) \\
\hline
\end{tabular}

annual per household payment for 10 years. Welfare estimates for Model 1 were significant for population improvements from endangered to threatened and endangered to not at risk. A recovery level of special concern was not significantly different from not at risk. Model 2 welfare estimates did not show sensitivity to scope; WTP values were positive to attain a species outcome better than endangered, but did not significantly differ across outcome levels. Model 3 welfare estimates showed some sensitivity to scope with willingness to pay differing between species outcomes of threatened and not at risk, but not differing between special concern and not at risk. Models 4 and 5 (with the largest samples) showed the greatest sensitivity to scope, with statistically significant differences in welfare estimates across all recovery levels.

Model 5 also introduced respondent socio-demographic characteristics, recognizing that the associated coefficients may not be consistently estimated because of potential endogeneity. We include this model to assess correlations between demographic characteristics and program choices. Respondents' household incomes, and if the respondent belonged to an environmental organization, were found to have statistically significant impacts on respondents' management program choices. WTP was found to increase by $\$ 0.82$ (with a standard error of 0.17 ) for each $\$ 1000$ increase in household income. As such, WTP by program was estimated using the mean household income of $\$ 72,000$. A value of $\$ 126$ (with a standard error of 31) to avoid the species status being endangered in 40 years and instead achieve a species status of not at risk was found. WTP values of $\$ 48$ (with a standard error of 32 ) and $\$ 92$ (with a standard error of 31 ) were found for threatened and special concern outcomes as opposed to an endangered outcome respectively. In addition to household income, if the respondent belonged to an environmental or conservation organization their WTP was estimated at an additional $\$ 97$ for any of the three program outcomes (see Table 4).

\section{Bivariate Probit Model}

Comparing the modeling of a subsample of respondents who indicated they viewed the surveys as consequential, as well as the full sample of respondents, the binary probit models and random effects probit models identified differences in WTP estimates between the two groups. WTP estimates were measurably higher for the consequential subsample. This is in contrast with the findings of Vossler et al., whose field experiment found that when respondents both believe their decisions are consequential and the information gathered will be used in such a way that maintains choice set independence and one-to-one matching between management projects, a modest positive bias in WTP estimates is removed. Rather these findings are in line with Vossler and Watson's later paper which compared survey and referendum results, and found an under-prediction of yes votes by the survey which disappeared when only respondents who believed the survey results to be consequential were examined.

To further examine the question of whether perceived consequentiality may be correlated with WTP, a bivariate probit model was employed. The first equation in the model matched that of models 1-4, with vote as the dependent variable and cost and program outcomes as the independent variables. For the second equation a binary variable equal to one if the respondent indicated they believed the survey would have an influence on policy making (was consequential) was the dependent variable, and gender, age and if the respondent belonged to an environmental organization were independent variables. All parameter estimates were significant at the 1 or $5 \%$ levels. The disturbance correlation was significant at the $1 \%$ level, indicating the likelihood of a respondent voting for a proposed management program is related to the respondents' perception of consequentiality (Table 5).

Model 6, Equation (1) parameter estimates found positive and significant WTP values for management programs benefitting a Pacific Rockfish at risk. Scope effects are reflected in the significant differences between WTP values for management programs resulting in varying species recovery level (Table 6). Model 6, Equation (2) parameter estimates indicate that the likelihood of a respondent believing that the survey responses would influence management programs for the species increases if the individual is male, or if the individual belongs to an environmental organization. In contrast, the likelihood is negatively correlated with age. Employing the bivariate probit approach does not result in statistically significant differences in WTP estimates, however it modestly improves the efficiency of the parameter estimates.

\section{Conclusion}

The results presented in this paper provide benefit estimates for the implementation of a range of management programs benefiting a rockfish species on Canada's Pacific coast. These 
TABLE 5 | Bivariate probit model.

\begin{tabular}{|c|c|}
\hline & Model 6 \\
\hline \multicolumn{2}{|l|}{ EQUATION 1: VOTE } \\
\hline \multirow[t]{2}{*}{ Constant } & $0.6047^{\star * *}$ \\
\hline & $(0.0464)$ \\
\hline \multirow[t]{2}{*}{ Cost } & $-0.0037^{\star \star \star}$ \\
\hline & $(0.0001)$ \\
\hline \multirow[t]{2}{*}{ Threatened } & $-0.2970^{\star \star \star}$ \\
\hline & $(0.0589)$ \\
\hline \multirow[t]{2}{*}{ Special concern } & $-0.1159^{\star *}$ \\
\hline & $(0.0577)$ \\
\hline \multicolumn{2}{|l|}{ EQUATION 2: YES INFLUENCE } \\
\hline \multirow[t]{2}{*}{ Constant } & $-0.9953^{* * *}$ \\
\hline & $(0.0985)$ \\
\hline \multirow[t]{2}{*}{ Male } & $0.2663^{\star \star \star}$ \\
\hline & $(0.0579)$ \\
\hline \multirow[t]{2}{*}{ Environmental Organization } & $0.5296^{\star * \star}$ \\
\hline & $(0.1044)$ \\
\hline \multirow[t]{2}{*}{ Age } & $-0.0074^{\star * *}$ \\
\hline & $(0.0020)$ \\
\hline Log likelihood & -2999.6130 \\
\hline \multirow[t]{2}{*}{ RHO (Disturbance Correlation) } & $0.1291^{* * *}$ \\
\hline & $(0.0383)$ \\
\hline Number of votes & 3291 \\
\hline Number of individuals & 1097 \\
\hline
\end{tabular}

TABLE 6 | WTP estimates per household per year for 10 years found through bivariate probit model.

\begin{tabular}{lc}
\hline & Model 6 \\
\hline Species outcome: Not at Risk & $\$ 162.91$ \\
Species outcome: Special Concern & $(10.58)$ \\
Species outcome: Threatened & $\$ 131.70$ \\
& $(11.25)$ \\
& $\$ 82.90$ \\
\hline
\end{tabular}

types of values are necessary for cost-benefit analyses undertaken for regulatory and legislative decisions on the implementation of such programs in Canada. The management programs involved actions and restrictions resulting in improved species status as defined by Canada's Species at Risk Act. The Species at Risk Act definitions were used for established species status reference points, however the study examined management actions with associated species outcomes rather than the listing or not listing of species under the Act. The economic values Canadians place on three management programs, each resulting in an improved status of the species from "endangered" to either "threatened," "special concern" or "not at risk," were estimated. Care was taken to specify in the survey instrument that the management program was directed at one of over 35 rockfish species. Despite this, it is still possible that a number of respondents interpreted the management programs as benefitting more than one species.

When designing the survey we sought to ensure the programs valued were possible and realistic, including their projected outcomes for the species, albeit hypothetical. The commercial fishing industry has demonstrated success reducing the total catch of some groundfish species in the Pacific groundfish fishery, including rockfish species, while maintaining a viable multi-species fishery of other species (Fisheries and Oceans Canada, 2009). Continual monitoring of what species are being caught where, and close communication between fishers about the locations of species to be avoided, is central to this effort. This indicates that management programs such as those presented here will not necessarily benefit other species. Future, valuations should be program-specific, and take into account all anticipated spillover benefits.

The range of household WTP values found indicates that respondents were sensitive to scope. The respondents were more willing to pay more for greater degrees of species improvement. This suggests that despite the majority of respondents indicating they were not familiar with the Species at Risk Act, they were able to grasp the concepts and understand what they were voting on. The finding that household income was significant in Model 4 further supports credibility, as it points to respondents considering their ability to pay when voting. Additional research on the relationship between WTP values and responses to consequentiality questions, including the assessment of endogeneity and the impact of various forms of consequentiality questions, should be considered given the finding of higher WTP values for respondents who believed the study would influence policy, and the significant correlation between consequentiality and the likelihood of voting.

\section{Study Approval}

Ethics approvals for the survey design and data analysis were obtained from the University of Alberta Research Ethics Board PER-ALES-NS, project numbers Pro00010526 and Pro00025927.

\section{Acknowledgments}

We thank Natalie Wright for her work and support through survey development and data collection, as well as Barbara Best, Richard Stanley, Sheri Andres and Keith Brickley for reviews and input through the various stages of study and survey development. 


\section{References}

Anderson, L. E., Lee, S. T., and Levin, P. S. (2013). Costs of delaying conservation: regulations and the recreational values of exploited and co-occurring species. Land. Econ. 89, 371-385. doi: 10.3368/le.89.2.371

Blumenschein, K., Blomquist, G. C., Johannesson, M., Horn, N., and Freeman, P. (2008). Eliciting Willingness to pay without bias: evidence from a field experiment. Econ. J. 118, 114-137. doi: 10.1111/j.1468-0297.2007.02106.x

Carson, R. T., and Groves, T. (2007). Incentive and informational properties of preference questions. Environ. Resour. Econ. 37, 181-210. doi: 10.1007/s10640007-9124-5

Fisheries and Oceans Canada. (2009). Evaluation of the Commercial Groundfish Integration Pilot Program. Ottawa, ON.

Government of Canada. (2006). 2006 Census of Population. Available online at: http://www12.statcan.ca/census-recensement/2006/index-eng.cfm

Grafton, Q., Adamowicz, W., Dupont, D., Nelson, H., Hill, R. J., and Renzetti, S. (2004). The Economics of the Environment and Natural Resources. Oxford: Blackwell Publishing Ltd.

Guilkey, D. K., and Murphy, J. L. (1993). Estimation and testing in the random effects probit model. J. Econom. 59, 301-317.

Jakobson, K. M., and Dragun, A. K. (2001). The worth of a Possum: valuing species with the contingent valuation method. Environ. Res. Econ. 19, 211-227. doi: 10.1023/A:1011128620388
Randall, A. (1997). The NOAA panel report: a new beginning or the End of an Era? Am. J. Agr. Econ. 79, 1489-1494.

Statistics Canada Report. (2007). Ageing Well. Ottawa, ON.

Vossler, C. A., Doyon, M., and Rondeau, D. (2012). Truth in consequentiality: theory and field evidence on discrete choice experiments. Am. Econ. J. Microecon. 4, 145-171. doi: 10.1257/mic.4.4.145

Vossler, C. A., and Watson, S. B. (2013). Understanding the consequences of consequentiality: testing the validity of stated preferences in the field. J. Econ. Behav. Organ. 86, 137-147. doi: 10.1016/j.jebo.2012.12.007

Conflict of Interest Statement: The lead author notes that the findings and results reported in this work do not necessarily reflect any explicit or implicit policy of Fisheries and Oceans Canada. The authors declare that the research was conducted in the absence of any commercial or financial relationships that could be construed as a potential conflict of interest.

Copyright (c) 2015 Forbes, Boxall, Adamowicz and De Maio Sukic. This is an openaccess article distributed under the terms of the Creative Commons Attribution License (CC BY). The use, distribution or reproduction in other forums is permitted, provided the original author(s) or licensor are credited and that the original publication in this journal is cited, in accordance with accepted academic practice. No use, distribution or reproduction is permitted which does not comply with these terms. 